\title{
A NOÇÃO DE ENUNCIADO DE MICHEL FOUCAULT: ONDE DIZER É PRODUZIR INOVAÇÃO
}

\section{THE NOTION OF STATEMENT FORMULATED BY MICHEL FOUCAULT: WHERE TO SAY IS TO PRODUCE INNOVATION}

\section{Kátia Menezes de Sousa*}

RESUMO: Este texto problematiza o tema da inovação no campo dos estudos linguísticos e discursivos e discute o papel da linguagem na construção das práticas de inovação. Toma-se, como categoria de análise, a noção de enunciado desenvolvida por Michel Foucault. A hipótese é a de que o mecanismo que permite a efetivação das técnicas de inovação é similar àquele que possibilita a existência das práticas discursivas, quando o enunciado é situado na ordem do acontecimento.

PALAVRAS-CHAVE: Enunciado. Inovação. Práticas Discursivas.

ABSTRACT: This work analyses the theme of innovation in the perspective of linguistic and discursive studies and discusses the language role in the construction of innovation practices. It considers, as category of analyze, the notion of statement formulated by Michel Foucault. The hypothesis is based on idea that the mechanism used to permit the realization of the innovation techniques is the same that makes possible the existence of discursive practices, when the statement is seen in the event order.

KEYWORDS: Statements. Innovation. Discursive Practices.

* Professora Associada da Faculdade de Letras da Universidade Federal de Goiás, doutorado em Linguística e Língua Portuguesa pela UNESP/Araraquara. E-mail: km-sousa@uol.com.br. 



\section{A NOÇÃO DE ENUNCIADO DE MICHEL FOUCAULT: ONDE DIZER É PRODUZIR INOVAÇÃO}

\section{CONSIDERAÇÕES INICIAIS}

Pensar em inovação na atualidade é considerar, em um plano mais superficial de elaboração, a ideia de invenção para exploração da economia e domínio de mercado. Seria a inovação, nesse sentido, um processo que inclui atividades técnicas, concessão, desenvolvimento, gestão e que resulta na comercialização de novos, ou melhorados, produtos. O caráter de novidade e de melhoria dos produtos é resultado do atendimento à máxima da eficiência que visa ao aumento da produção e à diminuição dos recursos despendidos. Por ser fator fundamental para o crescimento econômico, a inovação, além de constituir as investigações científicas em sua atividade prática, passou a compor teoricamente o campo dos conceitos e a definir os objetivos dos projetos incentivados pelas agências de fomento de pesquisas.

Quando se trata de produção de materiais de consumo, de processos financeiros, administrativos, de prestação de serviços, as pesquisas demandam conhecimentos de áreas já reconhecidas como produtoras de estudos e materiais, que garantam a majoração da eficiência do produto na vida prática da sociedade. Os conhecimentos elaborados e utilizados nas Ciências Biológicas e Exatas são inquestionavelmente reconhecidos e fundamenta- 
dores da existência de motivações visíveis para os avanços tecnológicos e econômicos de um país. Atuam no plano da visibilidade. Contudo, áreas como as das Ciências Humanas e Artes, geralmente, se apagam quando o assunto da pesquisa requer discussões que envolvam a inovação. Pensar a inovação na área de Letras, Linguística e Literatura, parece ser impossível, diante da definição que coloca a inovação como responsável pela eficiência dos produtos e processos, pela economia de recursos, pela competitividade do mercado e pelo crescimento econômico. No entanto, pode-se argumentar que esses resultados esperados com as técnicas de inovação não seriam alcançáveis fora das práticas discursivas e que elas se desenvolvem, em todas as etapas do processo, por meio daquilo que é dizível. Há que se considerar, também, o plano do enunciável.

É nesse sentido que este artigo pretende problematizar o tema da inovação no campo dos estudos linguísticos. Ou melhor, refletir sobre o papel da linguagem na construção das práticas de inovação e depreender dessa relação possibilidades de inovação no ensino. Para isso, tomar-se-ão as concepções de linguagem e discurso da Análise do Discurso de linha francesa e, como categoria de análise, a noção de enunciado desenvolvida por Michel Foucault, principalmente, na obra $A$ arqueologia do saber, em que intentou "definir o nível particular no qual o analista deve colocar-se para fazer aparecer a existência do discurso científico e seu funcionamento na sociedade" (FOUCAULT, 2011a: 193).

A metáfora da rede, utilizada por Foucault (1995) para definição de enunciado, já instiga à reflexão acerca das técnicas de inovação e as aproxima das propriedades do enunciado. Para ele, o enunciado tem sempre margens povoadas de outros enunciados; não há enunciado que não reatualize outros enunciados; o enunciado deve ser analisado (lido) ao nível de sua existência, pois ao que é dito não se pergunta o que esconde. Assim, a questão da relação entre enunciado e inovação se volta à problematização daquilo que pode ser efetivamente dito, no sentido de buscar compreender por que aquele enunciado apareceu e não outro em seu lugar.

$\mathrm{Na}$ tentativa de atingir o objetivo proposto, num primeiro momento, na seção 1, a inovação será discutida em sua relação com o conhecimento e, mais especificamente, com o processo de ensino e aprendizagem. Na seção 
2, serão tecidas considerações acerca da noção de enunciado para Foucault. Posteriormente, na seção 3, considerando a hipótese de que o mecanismo que permite a efetivação das técnicas de inovação é similar àquele que entra em jogo para a existência das práticas discursivas, situando o enunciado na ordem do acontecimento, serão analisadas algumas práticas discursivas da atualidade que têm como base e/ou objetivo a eficiência e o avanço científico e tecnológico. Finalmente, na quarta seção, a reflexão se pautará nos desdobramentos suscitados pela relação enunciado/inovação para a consideração de possibilidades de produzir inovação em outros espaços discursivos, como o escolar, por exemplo.

\section{QUE É INOVAR?}

Orientadas pelo argumento de que o conhecimento seja o elemento central das novas estruturas econômicas que surgem, as práticas discursivas e não-discursivas, que constroem o que é tido como inovador, apresentam, cada vez mais, um caráter heterogêneo em sua configuração concreta. Mesclando discursos de diferentes esferas do saber, a inovação passa a ser, supostamente, o veículo de transformação de conhecimento em riqueza e melhoria da qualidade de vida das sociedades contemporâneas.

Como práticas que se instauram nas mais variadas instâncias do conhecimento, as técnicas de inovação foram institucionalizadas, recebendo um estatuto de legalidade ao serem definidas e caracterizadas em legislação própria. Trata-se da Lei $n^{\circ} 10.973$, de 2 de dezembro de 2004, denominada "Lei da Inovação" (BRASIL, 2004)1, que reflete a necessidade de o país contar com dispositivos legais eficientes que contribuam para o delineamento de um cenário favorável ao desenvolvimento científico, tecnológico e ao incentivo à inovação. Conforme o Ministério da Ciência e Tecnologia (MCT) o desafio de se estabelecer no país uma cultura de inovação está amparado

1 Lei de Inovação. Disponível em: <http://www.planalto.gov.br/ccivil_03/_Ato2004 2006/2004/Lei/L10.973.htm>.

2 Sobre a Lei de Inovação. Disponível em < http://www.mct.gov.br/index.php/content/ view/8477.html> 
na constatação de que a produção de conhecimento e a inovação tecnológica passaram a ditar crescentemente as políticas de desenvolvimento dos países. A lei oficializa, assim, práticas que já estavam em desenvolvimento, conforme as necessidades de atendimento aos problemas da sociedade, fazendo com que a inovação, de resultado alcançado, passe a ser meta inicial, obrigatória, na produção de conhecimento.

Em seu primeiro Artigo, a Lei estabelece medidas de incentivo à inovação e à pesquisa científica e tecnológica no ambiente produtivo, com vistas à capacitação e ao alcance da autonomia tecnológica e ao desenvolvimento industrial do País. O inciso IV deste artigo define inovação como introdução de novidade ou aperfeiçoamento no ambiente produtivo ou social que resulte em novos produtos, processos ou serviços. A regulamentação se organiza em torno de três vertentes. A primeira diz respeito à "constituição de ambiente propício às parcerias estratégicas entre as universidades, institutos tecnológicos e empresas" (BRASIL, 2004). Nessa linha, a Lei contempla mecanismos de apoio e estímulo à constituição de alianças estratégicas e ao desenvolvimento de projetos cooperativos entre universidades, institutos tecnológicos e empresas nacionais, para "estruturação de redes e projetos internacionais de pesquisa tecnológica; ações de empreendedorismo tecnológico; e criação de incubadoras e parques tecnológicos" (BRASIL, 2004). A segunda vertente prevê o "estímulo à participação de instituições de ciência e tecnologia no processo de inovação" (BRASIL, 2004). Nessa vertente, a Lei faculta às Instituições de Ciência e Tecnologia (ICT) celebrar contratos de transferência de tecnologia e de licenciamento de patentes de sua propriedade, prestar serviços de consultoria especializada em atividades desenvolvidas no âmbito do setor produtivo, assim como estimular a participação de seus funcionários em projetos onde a inovação seja o principal foco. A terceira vertente garante o incentivo à inovação na empresa. Os dispositivos legais explicitados nessa vertente buscam estimular uma maior contribuição do setor produtivo em relação à alocação de recursos financeiros na promoção da inovação. Mediante contratos ou convênios específicos tais recursos devem ser ajustados entre as partes, considerando ainda as prioridades da política industrial e tecnológica nacional. Ainda conforme documento do MCT, o marco legal representa um amplo con- 
junto de medidas cujo objetivo maior é ampliar e agilizar a transferência do conhecimento gerado no ambiente acadêmico para a sua apropriação pelo setor produtivo, estimulando a cultura de inovação e contribuindo para o desenvolvimento industrial do país.

Apesar de não contemplar em sua definição o papel da Educação, a Lei no 10.973 , ao considerar a inovação como introdução de novidade ou aperfeiçoamento no ambiente produtivo ou social que resulte em novos produtos, processos ou serviços, deixa uma possibilidade para que questões mais diretamente ligadas à Educação possam compor projetos voltados para o aperfeiçoamento e inovação das práticas de ensino, o que pode resultar em um ambiente mais produtivo de construção do conhecimento e em mais sucesso no processo ensino-aprendizagem. O trabalho com as linguagens e os discursos integram, de forma constitutiva, qualquer projeto educativo e, mais ainda, qualquer projeto de inovação. Não se pode alcançar autonomia tecnológica e desenvolvimento industrial do país sem ter de lidar com um trabalho que se dá com a linguagem, na leitura, na interpretação de textos verbais e não-verbais, na escrita. Além disso, apenas com o domínio da materialidade linguística, com suas regras e exceções, não é possível a conquista da autonomia ou o desenvolvimento de dada tecnologia, pois o domínio dos saberes exige uma capacidade muito mais ampla, da qual dependem os sujeitos, para relacionar enunciados de esferas e momentos diferentes e refletir sobre as redefinições de objetos científicos e temas da atualidade, construídas pelo rompimento das fronteiras entre os diversos discursos.

Uma das vertentes da Lei 10.973 prevê a integração entre o ambiente acadêmico e o setor produtivo, mas o papel da linguagem não é considerado. A ideia já difundida é a de que a esfera acadêmica se refira a algumas áreas do conhecimento que têm como objeto de pesquisa o produto de mercado ou de tecnologia. Existe, de fato, uma limitação de acesso ao lugar ocu

pado por quem pode falar e fazer inovação no país. Os conhecimentos da área de Humanas não têm apontado para a posição que deve ocupar o sujeito para falar neste lugar, o da inovação. Dessa forma, a questão, como colocada por Foucault (2011b), não deve consistir mais em procurar saber como o mundo pode ser vivido, experimentado, atravessado pelo sujeito. O problema deve ser colocado no sentido de saber quais são as condições 
impostas a um sujeito qualquer para que ele possa introduzir-se, funcionar, servir de nó na rede sistemática do que nos cerca. Portanto,

a descrição e a análise não terão mais como objeto o sujeito em suas relações com a humanidade, mas terão a ver com o modo de existência de alguns objetos (como a ciência) que funcionam, se desenvolvem, se transformam, sem nenhuma espécie de referência a alguma coisa que seria o fundamento intuitivo de um sujeito.

(FOUCAULT, 2011b: 50).

O posicionamento do sujeito não é conquistado por sua intuição, mas por seu pensamento construído em sua relação com os objetos, intermediada pelos enunciados. Talvez falte divulgação dos trabalhos desenvolvidos nesta área e principalmente das pesquisas que têm se voltado para as questões de linguagem e de discurso, pois "a maneira de utilizar a linguagem em uma dada cultura e em um dado momento encontra-se intimamente ligada a todas as outras formas de pensamento" (FOUCAULT, 2011b: 50).

Nesse sentido, há trabalhos publicados que discutem a relação entre Educação e Inovação, como o de Luckesi (2012), em que é possível estender para uma reflexão sobre o discurso nas práticas de inovação. Para o autor (2012: 15), "inovar é propor e construir novas possibilidades que redundam em 'produtos' que sejam adequados, úteis e belos”. Ele entende por produto "o resultado da ação de alguém que cria, recria ou inova, produzindo bens materiais, assim como bens culturais, seja como vida vivida (traduzida em objetos materiais) ou como vida vivente (traduzida em diversas expressões da vida)". Se a Lei no 10.973 prevê um ambiente produtivo ou social, o espaço escolar também aí está contemplado, sendo o produto mais que objetos materiais, mas sujeitos capazes de criar e recriar.

Considerados assim o ambiente e o produto, a inovação ganha novos contornos e tem ampliado o seu alcance, podendo responder "a anseios humanos, seja encontrando soluções pragmáticas para a funcionalidade da vida, seja imprimindo beleza àquilo que se produz, que se faz, que se expressa" (LUCKESI, 2012: 16). A inovação não se concretiza apenas no lançamen- 
to de um produto novo no mercado, mas também nas formas de divulgação e de negociação desse produto. A tecnologia deve alcançar também as formas de dizer para que a inovação se dê na transformação do belo em mais belo, do necessário em imprescindível. A publicidade já atua nessa área de forma exemplar. E não cria seus produtos sem que haja um domínio dos discursos que circulam na sociedade e sem que tenha havido um trabalho de educação. Não há trabalho em educação que não traga, em seu processo, a inovação, que se dá sobre os conhecimentos e sobre os próprios sujeitos do conhecimento. Nesse espaço marcado por uma heterogeneidade discursiva,

a inovação se dá seja nas proposições filosóficas, na prática de investigação científica; seja na proposição de soluções novas, tanto para o sistema de ensino como para o ensino-aprendizagem, nos recursos para o ensino e para a aprendizagem; seja nas relações interpessoais entre profissionais de uma instituição educativa, como também entre educadores e educandos, entre outras possibilidades.

(LUCKESI, 2012: 17)

A inovação também pode ocorrer da conjugação entre teoria e prática, criando espaço para o pensar, o refletir sobre os conceitos das teorias, dos vários conhecimentos, sobre as práticas que movimentam a sociedade rumo aos diferentes objetivos (consumo, lucro, bem-estar, qualidade de vida, etc.). A reflexão exige que se estabeleçam relações entre o que é dito nas teorias, nas histórias dos homens, nas decisões políticas, nos veículos de mídia para que possa haver uma tomada de consciência em torno da razão de por que agir de uma forma ou de outra. É o exercício da crítica, que pressupõe o pensamento, pois, conforme Foucault (2010), numa reflexão sobre a importância de pensar, fazer a crítica é tornar difíceis os gestos mais simples, por isso ser a crítica indispensável para qualquer transformação. A crítica pelo exercício do pensamento exige a construção de relações entre as práticas discursivas, os conhecimentos, entre teoria e prática, pois "uma transformação que ficasse no mesmo modo de pensamento, uma transformação 
que só fosse uma certa maneira de melhor ajustar o mesmo pensamento à realidade das coisas não passaria de uma transformação superficial" (FOUCAULT, 2010: 356-357).

Pelo que se lê sobre a divulgação de Ciência e Tecnologia, a palavra que resume a ação fundamental das práticas científicas e de inovação na atualidade é relação, associação. Por isso, o caráter de novidade da noção de enunciado formulada por Foucault, ao tratá-lo como unidade do discurso, da análise reflexiva das palavras e das coisas e como via de possibilidade de existência dos saberes e do exercício do poder.

\section{O ENUNCIADO: NÓ NA REDE DISCURSIVA}

A ideia de rede tem configurado os sentidos das ações das novas tecnologias e da Ciência e Inovação. É um termo utilizado por Michel Foucault já na obra $A$ arqueologia do saber, de 1969, para demonstrar que o enunciado é sempre um acontecimento, porque está ligado à articulação de uma palavra e, ao mesmo tempo, a uma existência remanescente no campo de uma memória, ou na materialidade de qualquer forma de registro. $\mathrm{O}$ enunciado é único como todo acontecimento, porém aberto à repetição, à transformação, à reativação, por estar ligado tanto às situações que o provocam, quanto a enunciados que o precedem e o seguem. Essa capacidade de transformação, reativação, de surgir como acontecimento, parece ser o fundamento que define as práticas de inovação. Portanto, em termos de reflexão sobre a linguagem, tal fundamento já tinha sido detectado, mas como uma propriedade do enunciado.

Conforme Foucault (1995), o discurso é constituído por um conjunto de sequências de signos, enquanto enunciados, isto é, enquanto lhes possam atribuir modalidades particulares de existência por terem sido efetivamente produzidas. Pelo fato de o enunciado se referir ao que realmente pôde ser dito; ser constituído por uma materialidade que lhe dá substância, suporte, lugar e uma temporalidade que lhe asseguram uma identidade; possuir um valor, que caracteriza o lugar em que aparece, a sua capacidade de circulação e de troca, sua possibilidade de transformação na administração de 
seus raros recursos e de sua pobreza enunciativa; portar uma exterioridade paradoxal e formas de acúmulo que garantem os jogos da memória e do esquecimento, é que o discurso, assim concebido, "aparece como um bem - finito, limitado, desejável, útil - que tem suas regras de aparecimento e também suas condições de apropriação e de utilização; um bem que coloca [...] a questão do poder, um bem que é, por natureza, o objeto de uma luta, e de uma luta política." (FOUCAULT, 1995: 139).

Os enunciados, para Foucault (1995), passam por uma reatualização, e isso é visível na emergência dos enunciados que identificam e configuram o caráter de inovação na atualidade. Para definir enunciado, Foucault recorre a construções como: "a sua capacidade de circulação e de troca", para caracterizar o valor que qualquer enunciado carrega; "sua possibilidade de transformação na administração de seus raros recursos e de sua pobreza enunciativa", para mostrar que o enunciado é resultado de um trabalho de melhoria do produto com o aproveitamento positivo dos parcos recursos; "um bem", para concluir que o enunciado é um objeto de luta, de poder.

Ao descrever a função enunciativa, Foucault (1995) situa o enunciado num espaço que o conserva ou o elimina. Esse espaço pode ser distribuído em três partes, conforme Deleuze (2005). A primeira compõe um espaço colateral, associado ou adjacente, formado por outros enunciados que fazem parte do mesmo grupo. Assim, um enunciado tem sempre margens povoadas de outros enunciados, e o campo associado é constituído pelo conjunto das formulações a que o enunciado se refere, seja para repeti-las, seja para modificá-las ou adaptá-las, ou se opor a elas, ou para falar de cada uma delas; não há enunciado que, de uma forma ou de outra, não reatualize outros enunciados (FOUCAULT, 1995).

A segunda parte do espaço refere-se ao espaço correlativo, em que o enunciado se encontra relacionado com seus sujeitos, seus objetos, seus conceitos. Foucault (1995) esclarece que o enunciado está ligado a um conjunto de domínios, em que os objetos podem ou não aparecer, a uma determinada posição que pode e deve ocupar o indivíduo para ser seu sujeito, a certos esquemas discursivos que permitem a construção de conceitos, como também sua transformação ou substituição, que serão formulados por meio de enunciados para que possam ser chamados de seus pelos objetos. 
A terceira parte é a das práticas não-discursivas (instituições, acontecimentos políticos, processos econômicos), em que os enunciados remetem a um meio institucional sem o qual os objetos surgidos nesse lugar não poderiam ser formados, nem o sujeito que fala desse lugar.

Para a produção de objetos, as práticas discursivas são garantidas pela realização de certos conjuntos de enunciados e, como pontua Foucault (1995: 138), a análise dos enunciados deve "determinar o princípio segundo o qual puderam aparecer os únicos conjuntos significantes que foram enunciados”. A tarefa do analista de enunciados, dessa forma, deve se centrar em três princípios: o da raridade, o da exterioridade e do acúmulo.

Os enunciados são raros, pois nem tudo é sempre dito, estão sempre em déficit, já que são inseparáveis de uma lei e de um efeito de raridade. A presença de um enunciado inibe a entrada de outro, mas não há nada embaixo dele, está inteiro na superfície e ocupa um lugar que só a ele pertence e deve ser analisado em seu valor. Conforme Foucault, os enunciados são coisas que se transmitem e se conservam, que têm um valor, e das quais procuramos nos apropriar; que repetimos, reproduzimos e transformamos. Muitas coisas são ditas sobre os objetos tomados pela inovação na atualidade, algumas são ditas há muito tempo e foram conservadas, outras transformadas conforme a constelação discursiva em que os objetos são tratados e conforme as práticas constitutivas do tipo de sociedade que se tem hoje.

Os enunciados devem ser analisados em sua exterioridade, como o conjunto das coisas ditas, as relações, para apreender sua própria irrupção no lugar e no momento em que se produziu, para reencontrar sua incidência de acontecimento. Importante acentuar aqui que a exterioridade não remete a uma forma de interioridade como sujeito fundador, transcendental, soberano, mas aos efeitos próprios do campo enunciativo por meio das diferentes formas da subjetividade que fala. Tedesco (2007: 146) demonstra que um fato subjetivo é um efeito do encadeamento de práticas diversas, e a produção de realidades processa-se na pluralidade de discursos advindos dos diversos saberes e práticas. Ou seja, no conjunto de falas, a forma-sujeito constitui-se como objeto discursivo. Assim, um conjunto de discursos faz os objetos comportarem-se de uma determinada forma ou de outra, e os sujeitos acreditam serem dotados de uma natureza regida por princípios 
constantes. Os dizeres heterogêneos compõem a produção de um si mesmo que se pretende agente da enunciação.

Por fim, Foucault (1995) explica que o enunciado é o objeto específico de um acúmulo, através do qual ele se conserva, se transmite ou se repete. Deleuze (2005) lembra que o acúmulo não é o contrário da raridade, mas efeito dessa mesma raridade. Ou seja, é por meio desta última que a análise deve procurar que modo de existência pode caracterizar os enunciados ao longo do tempo em que subsistem, em que se conservaram, em que são reativados, utilizados, esquecidos ou mesmo destruídos (FOUCAULT, 1995).

As técnicas de inovação remetem-nos à arqueologia do saber de Foucault, pois, seguindo o comentário de Deleuze (2005), pode-se considerar que ela apresenta dois elementos de estratificação: o enunciável e o visível, as práticas discursivas e as não-discursivas. Na formação dos saberes, o visível e o enunciável se inserem um no outro e não param de se interpenetrar, mas há, entre os dois planos, diferenças de natureza. Assim, falar não é ver e, se o enunciado tem um objeto, é um objeto discursivo que lhe é próprio, que não é isomorfo ao objeto visível. Foucault demonstrará essa tese da diferença, por exemplo: no comentário à tela de Magrite, em que texto e figura se separam com a presença do desenho do cachimbo, e o enunciado que deveria apontar para "isto é um cachimbo", torna-se "isto não é um cachimbo"; na descrição, em História da loucura, do hospital geral, que, enquanto forma do conteúdo ou lugar de visibilidade da loucura, não tem sua origem na medicina, mas na polícia; na análise da prisão, em Vigiar e Punir, como visibilidade do crime não derivada do direito penal como forma de expressão, mas de uma perspectiva disciplinar que levaria ao dito "isto não é uma prisão". Portanto, é pela análise das relações possibilitadas pelos enunciados que o emaranhado de discursos pode fazer aparecer ou desaparecer os objetos que entram nas práticas ditas de inovação.

Ao tratar da raridade, Foucault (1995) explica que interpretar é uma maneira de reagir à pobreza enunciativa e de compensá-la pela multiplicação do sentido e que analisar uma formação discursiva é procurar a lei de sua pobreza, é medi-la e determinar-lhe a forma específica. 


\section{ENUNCIADO E INOVAÇÃO: AS CONDIÇÕES DE EXISTÊNCIA}

A inovação passa por transformações, pois se encontra em espaços recobertos pela ampla rede de comunicação que cumpre a tarefa de problematizá-la para continuar cumprindo sua função: dizer o que a inovação tem de ser. Aliás, pode-se pensar que o enunciado, sendo da ordem do acontecimento e, portanto, "nó na rede discursiva", tem, também, sua consistência na problematização. Em "O cuidado com a verdade”, Foucault (2004) explica que a noção de problematização unifica seus estudos e a define como o conjunto das práticas discursivas ou não-discursivas que faz alguma coisa entrar no jogo do verdadeiro e do falso, constituindo o objeto para o pensamento, seja sob a forma da reflexão moral, do conhecimento científico, da análise política, etc.

Nesse sentido, a inovação só eclode com a entrada da subjetividade humana, ou seja, com o trabalho de interpretação. Para Foucault (2000a), a interpretação nunca pode se concluir, e nada há de primeiro a interpretar, pois tudo já é interpretação; cada signo é nele mesmo não a coisa que se oferece à interpretação, mas interpretação de outros signos. Logo, podemos pensar que os enunciados, já em sua emergência, são constitutivos de um processo de inovação, e o que deve ser caracterizado como inovação é a coexistência de enunciados dispersos e heterogêneos.

Para exemplificar a heterogeneidade na formação dos enunciados, Foucault (2000b: 100-101) utiliza o discurso clínico para demonstrar que sua unidade

não é uma forma determinada de enunciados, mas o conjunto de regras que, simultânea e sucessivamente, tornou possível não somente descrições puramente perceptivas, mas também observações mediatizadas por instrumentos, protocolos de experiências de laboratórios, cálculos estatísticos, constatações epidemiológicas ou demográficas, regulamentos institucionais, decisões políticas. 
Em qualquer campo do saber, há um sistema que rege à confirmação de certos enunciados a partir de outros e à maneira pela qual eles se implicam ou se excluem. Nos textos veiculados pela mídia, sejam eles de divulgação científica ou de publicidade, nota-se a coexistência de enunciados de diferentes saberes constituindo os discursos. A análise da circulação e da troca de enunciados no campo midiático, na atualidade, permite descrever os discursos que constituem as práticas de inovação e o tipo de sociedade produzido pela rede enunciativa tecida nos diferentes sistemas de formação dos discursos. Essa relação é possível porque os dispositivos midiáticos trabalham para ter o controle sobre esse bem, que é o discurso, atuando ativamente nos processos de identificação dos sujeitos de uma sociedade. É pela mídia que grande parte da população conhece as novidades desenvolvidas para os mais diferentes produtos. Assim, os discursos veiculados, sustentados, descartados, ou mesmo silenciados, pela mídia, constituem o arquivo, que define, nos termos de Foucault (1995), o sistema de enunciabilidade, de formação e transformação dos enunciados, a lei do que pode ser dito. Se o que é dito o é no interior das regras do arquivo, a análise dos enunciados comporta, conforme Foucault (1995), a orla do tempo que cerca nosso presente, que o domina e o indica em sua alteridade, instaura o corte que nos separa do que não podemos mais dizer e do que fica fora de nossa prática discursiva. As fronteiras das formações discursivas, que margeiam os enunciados e os cortes que definem a existência de certos discursos, limitam seu intercâmbio, sua comunicação e sua apropriação, o que justifica a análise dos enunciados midiáticos numa sociedade que luta para ter o controle e, paradoxalmente, contra ele. Assim, neste trabalho, alguns enunciados que serão analisados dão forma de existência aos discursos de inovação na atualidade brasileira, oferecendo-lhes tratamento de arquivo, ou seja, como "uma existência acumulada dos discursos" (FOUCAULT, 2000c: 72).

$\mathrm{O}$ recorte requerido por esta curta reflexão se liga à elaboração de $\mathrm{Mi}$ chel Foucault acerca do enunciado e da sociedade de controle que começa a se desenhar no século XVIII com o aparecimento de um poder que é, ao mesmo tempo, disciplinador e normalizador, que não se exerce mais sobre os corpos individualizados, mas se concentra na figura do Estado, sendo exercido com pretensões de administrar a vida e o corpo da população. No 
texto "A governamentalidade", parte de uma aula ministrada em 1978, Foucault (2003) explica que, após o século XVIII, a arte de governar ligou-se à emergência do problema da população, com a expansão demográfica, e seu objetivo passou a ser o de melhorar o destino das populações, de aumentar sua duração de vida e sua saúde. Os instrumentos utilizados para alcançar esse objetivo são centrados essencialmente na própria população sobre a qual o governo age diretamente por meio de campanhas ou, indiretamente, estimulando, sem que as pessoas o percebam, a taxa de natalidade, ou dirigindo para certas regiões e para dadas atividades os fluxos de população.

Numa conferência proferida no Rio de Janeiro em 1974, Foucault (2003) levanta a hipótese de que o capitalismo socializou um primeiro objeto que foi o corpo enquanto força de produção, e de que o controle da sociedade sobre os indivíduos não se operava simplesmente pela consciência ou pela ideologia, mas começava no corpo, com o corpo. Conclui, assim, que a sociedade capitalista investiu no biológico, no somático, no corporal, pois o corpo é uma realidade biopolítica, e a medicina uma estratégia biopolítica. Mesmo por uma investigação sem pretensão científica, é possível perceber que os enunciados que compõem as plataformas políticas ou a interação dos governos com a população referem-se, sob vários aspectos, ao interior e ao exterior dos corpos das pessoas, para a garantia de saúde, bem-estar, beleza e longevidade.

Como forma de conquistar ou permanecer no mercado, o discurso da inovação tem sido muito explorado para marcar a diferença entre produtos de um mesmo segmento ou para qualificar as ações de empresas, indústrias, dos governos. A inovação aparece como argumento para a divulgação de produtos que vão desde aqueles voltados para a saúde, passando pela beleza, longevidade e pelo bem-estar, até aqueles que oferecem o luxo e a sofisticação. Relativamente à saúde, por exemplo, as clínicas e hospitais têm oferecido não só o tratamento de doenças, mas diagnósticos mais precisos, novas tecnologias, comodidade, conforto e até sofisticação, marcada pela arquitetura do prédio. É o que se lê em um anúncio publicitário que traz a imagem externa de um hospital e informa: "A fachada tem linhas dinâmicas. A nova saúde de Pernambuco também”. ${ }^{3}$ Os anúncios mostram que o espaço

3 Disponível em: http://www.linkpropaganda.com.br/linktrabalhos/hospital-miguel-arraes-2/ 
do hospital incorporou as características de outros espaços, acompanhando a máxima da inovação e as técnicas do biopoder. A questão não é só de saúde, mas de bem-estar, felicidade do cliente que precisa se sentir como se estivesse em casa, ou em um hotel ou resort. O espaço é marcado por uma heterogeneidade e as fronteiras das formações discursivas se ampliam, reconfigurando os papéis de quem ocupa tais espaços.

A ideia de empresa transforma a relação entre os sujeitos que ocupam o espaço hospitalar. O paciente se torna cliente, e os profissionais - mais que médicos, enfermeiros, atendentes - são gestores, administradores, que buscam no discurso empresarial o modelo de práticas tanto discursivas quanto não-discursivas. Os fornecedores de materiais hospitalares também seguem a nova ordem discursiva e apresentam seus produtos por meio de construções discursivas que remetem às técnicas da inovação, que ganha existência pelos produtos e pelo discurso. Os anúncios publicitários desse setor apresentam seus produtos, geralmente, redimensionando suas funções por meio da linguagem e assegurando um posicionamento enunciativo determinado pela inovação. São construções do tipo "Tecnologias Inovadoras e Sustentáveis na área médico-hospitalar", "produtos diferenciados, através da importação, de qualidade internacional comprovada", etc.

A Educação, em poucos anúncios, constitui o argumento de inovação, como em: "Houve um trabalho intenso pela educação permanente, linhas de cuidado com a saúde da criança, atenção ao pré-natal, vigilância da tuberculose, saúde mental e acolhimento. Foram realizadas inúmeras oficinas de trabalho com as equipes e o Núcleo de Apoio à Saúde da Família”."

Deleuze (1992: 221), analisando as estratégias das sociedades de biopoder que marcam a forma de estar no mundo na contemporaneidade, considera que os controles funcionam como uma moldagem autodeformante que mudasse continuamente, a cada instante, "ou como uma peneira cujas malhas mudassem de um ponto a outro." Nesse sentido, "a empresa substitui a fábrica, e a empresa é uma alma, um gás." Ela, operando dentro de um sistema de prêmios, impõe uma modulação para cada salário, "introduz o tempo todo uma rivalidade inexpiável como sã emulação, excelente motivação que contrapõe os indivíduos entre si e atravessa cada um, dividindo-o

4 Disponível em: http://www.fiocruz.br/ccs/cgi/cgilua.exe/sys/start.htm?infoid=5152\&sid=9 
em si mesmo." O autor, ainda, analisa que o princípio modulador do salário por mérito tenta a própria Educação, e " a formação permanente tende a substituir a escola, e o controle contínuo substitui o exame." Tornar-se empresa parece, assim, produzir inovação.

Como exemplo dessa consideração de Deleuze, a inovação também compõe temas de concursos para premiação de trabalhos na área da saúde, como se vê na notícia divulgada pela $\mathrm{UNESCO}^{5}$ :

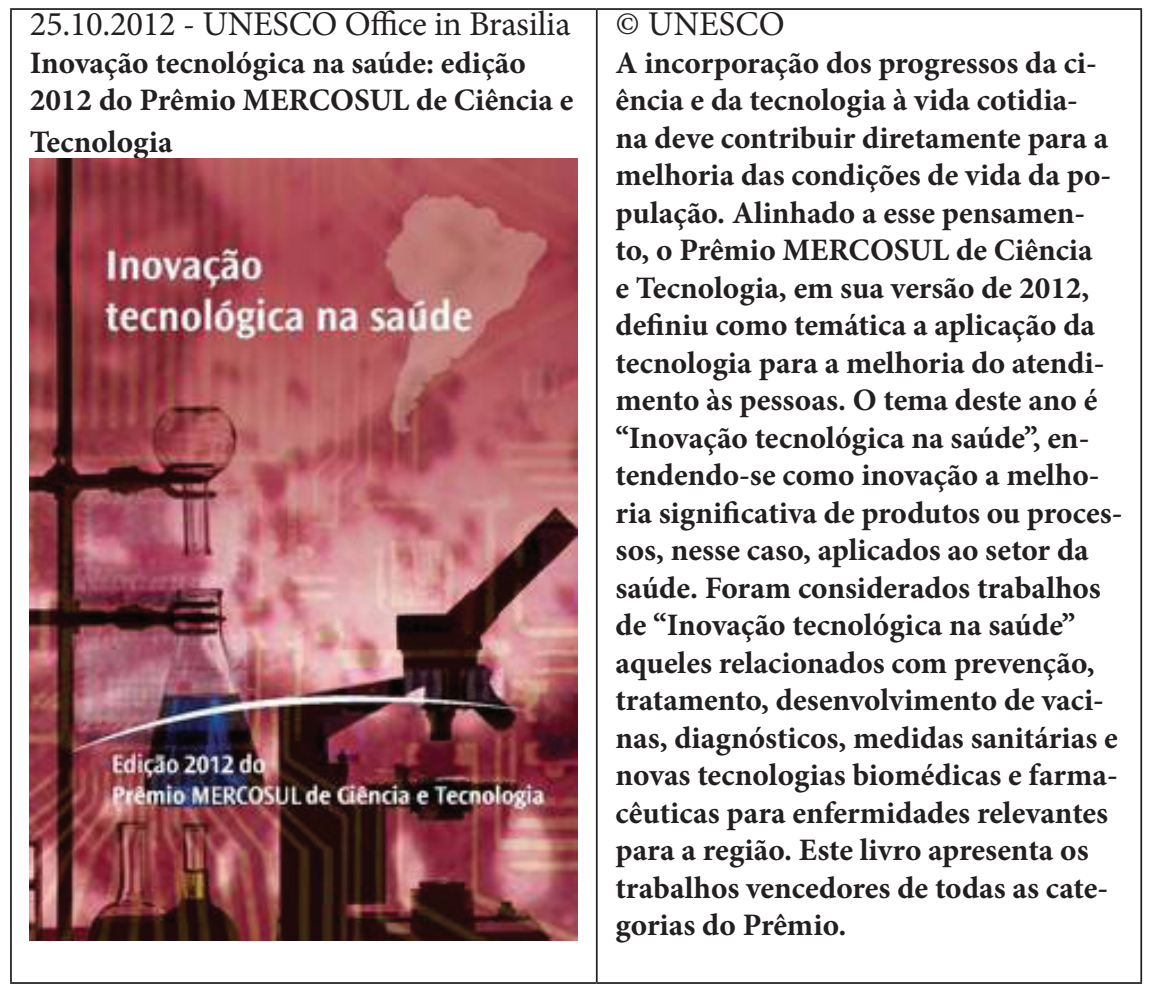

Integrado às estratégias do biopoder, o prêmio de Ciência e Tecnologia prevê a melhoria das condições de vida da população com a contribuição direta dos progressos científicos e entende inovação na saúde como "a melhoria significativa de produtos ou processos" relacionados às diferentes

5 Disponível em: http://www.unesco.org/new/pt/brasilia/about-this-office/single-view/news/inovacao_tecnologica_na_saude_edicao_2012_do_premio_mercosul_de_ciencia_e_tecnologia 
práticas que constituem a esfera da saúde, como a prevenção de doenças, vacinação, saneamento, etc. O poder nas sociedades de controle é exercido de forma sutil, despretensiosa, constituindo, na área da saúde, uma medicina social que tem como pano de fundo uma certa tecnologia do corpo social, conforme mostra Foucault (2003).

A saúde se configura como um lugar estratégico para o exercício do biopoder, pois lida com as possibilidades de manutenção e prolongamento da vida. A população deseja viver mais e melhor e se torna refém de um controle que se renova a cada dia para oferecer formas de estar bem no mundo. De acordo com Foucault (2001), o biopoder sucede o poder de soberania, mantendo a relação vida/morte. Enquanto para o soberano a máxima era a de fazer morrer e deixar viver, para o biopoder, a ordem é fazer viver e deixar morrer. A partir do século XIX, a lógica deixa de ser a da soberania e passa a ser a lógica biológica. Assim, torna-se necessário falar de biopoder para designar aquilo que faz entrar a vida e seus mecanismos no domínio dos cálculos explícitos e faz do poder-saber um agente de transformação da vida humana. Fica instaurada uma preocupação com o bem-estar em termos de necessidade e felicidade das pessoas e com novas técnicas para maximizar a vida. O "fazer viver", a que se refere Foucault (1999), segundo Pelbart (2003), marca o biopoder e é revestido de duas formas: a disciplina e a biopolítica. As disciplinas, baseadas no adestramento do corpo, na otimização de suas forças, na sua integração em sistemas de controle, tomam o corpo como máquina, sujeito assim a uma anátomo-política. A biopolítica mobiliza outro componente estratégico que é a gestão da vida incidindo não mais sobre os indivíduos, mas sobre a população, enquanto espécie. Aqui é o corpo atravessado pela mecânica do vivente, como suporte de processos biológicos. Trata-se da biopolítica da população, em que a ênfase recai sobre o nascimento e a mortalidade, o nível de saúde, a longevidade.

Instaura-se, assim, uma tecnologia de duas faces que, na leitura de Pelbart (2003), caracteriza o biopoder, por um lado, com as disciplinas, as regulações, a anátomo-política do corpo; por outro lado, com a biopolítica da população, a espécie, as performances do corpo, os processos da vida. Ao lado da submissão dos corpos através das escolas, quartéis, fábricas, surgem os problemas de natalidade, longevidade, saúde pública, habitação, imigração. 
Apesar de ter formulado tais conceitos ainda nos anos de 1970, o legado da reflexão de Foucault, conforme analisa Duarte (2008), dissemina ideias, vinte anos depois, e renova campos distintos da investigação das Ciências Humanas, instigando a formulação de novos problemas e novas possibilidades de análise. $\mathrm{Na}$ atualidade, os conceitos de biopoder e biopolítica ganham importância capital nas análises dos problemas políticos e sociais.

As práticas da contemporaneidade são marcadas por essas tecnologias apontadas por Foucault. São muitos os exemplos que comprovam a eficácia dessa relação poder/saber. Além da saúde, as tecnologias de controle pelo biopoder alcançam as diferentes instituições, as mais diversas instâncias do conhecimento, as práticas discursivas e as não-discursivas. A obrigatoriedade de ser saudável, belo, sempre jovem e feliz pode ser constatada não só na heterogeneidade que marca as instâncias de saúde, mas também em outras esferas, como a indústria e o comércio, que inovam, utilizando a estratégia de colocar em associação discursos de diferentes práticas.

É o que ocorre com a moda, em que o esperado é que se lidasse com a roupa para cobrir os corpos, levando em consideração o clima, o tipo de evento, a idade do cliente, mas que passa a considerar outras questões para não ficar fora do movimento de inovação. Assim, ouve-se falar de "tecidos inteligentes" que inovam por possuírem componentes digitais da eletrônica e da computação embutidos em sua estrutura. Fazem parte da "tecnologia vestível", como é designada em sua instância de enunciação. Como informa o site Wikipédia', "o campo da integração entre fibras têxteis e componentes eletrônicos avançados é por vezes chamado 'fibertrônica". A inovação, por ter em sua base a relação entre diferentes formações discursivas, produz enunciados com uma nova materialidade linguística, recriando termos para nomear seus novos objetos.

A moda aparece também relacionada ao meio ambiente, à ideia de sustentabilidade, como pode ser visto na divulgação de um site de "Ecomoda":

Numa época em que o desenvolvimento sustentável e a preservação do meio ambiente são preocupações recor-

${ }^{6}$ Disponível em: <http://pt.wikipedia.org/wiki/Tecido_inteligente>

7 Disponível em: <http://vivapernambuco.com.br/site/index.php/blogs/2-blog-01/2401-moda-ecologica-estimula-consumo-consciente> 
rentes, é necessário colaborar na propagação da ideologia do "ecologicamente correto". A indústria têxtil um setor significativo da economia brasileira - aderiu à "onda verde" e, atualmente, a moda ecológica é responsável por movimentar entre $R \$ 270$ e $R \$ 362 \mathrm{mi}$ thões por ano.

A inovação ganha existência na interação entre moda e meio ambiente pelo fato de colaborar com as "preocupações recorrentes [...] da ideologia do ecologicamente correto". Esse é o motivo nobre, que é explicitado num primeiro momento e que garante o status de inovação. Mas outro motivo aparece em segundo plano, que é o relativo ao lucro pelo movimento significativo da economia. Aqui também a materialidade linguística passa por um processo de recriação, colocando em cena construções como ecomoda, onda verde, biojoias, etc.

Os produtos e as técnicas de beleza também exploram o viés científico e tecnológico que marca a inovação. Em várias revistas nacionais, o avanço científico no desenvolvimento de cosméticos é noticiado e apresentado como matéria de capa. É o caso da revista Superinteressante de janeiro de 1997, que traz na capa o título "Cosméticos científicos" e, como subtítulo, o enunciado "Agora a beleza virou assunto de cientistas", construindo uma nova concepção para os cosméticos. No interior da edição, a matéria divulga a ideia de que os produtos de beleza são, a partir dos avanços científicos, tratamentos. No trecho da mesma matéria, pode-se comprovar que a beleza, além de garantir um lucro certo por ser desejada pela maioria das pessoas, é também científica.

No ano passado, os brasileiros gastaram 906 milhões de dólares tentando apagar as rugas. Para quem acha que eles compraram ilusão em potes e bisnagas, os pesquisadores da área da Cosmiatria - o estudo médico e bioquímico dos cosméticos - rebatem: suas novas poções são científicas. Desde o dia $1^{\circ}$ deste mês, a Sociedade Européia das Indústrias de Cosméticos proíbe que um produ- 
to acene com efeitos mágicos se eles não forem provados. (Revista Superinteressante, 1997: 38, grifos meus)

Para atender a esse mercado promissor economicamente e útil para a garantia do bem-estar e felicidade dos indivíduos, uma nova especialidade médica é criada, a Cosmiatria. Identifica-se, assim, um saber-poder autorizado a criar novos objetos, conceitos e práticas.

Faltaria espaço para demonstrar com exemplos o vasto alcance empreendido pelas tecnologias de inovação, seja em produtos, processos ou serviços. Elas se fazem presentes no atendimento aos clientes, na preparação e realização de viagens turísticas, nos serviços bancários, por exemplo, com enunciados como: "O Banco investe forte no Brasil e faz isso investindo em sustentabilidade”. A indústria e o comércio automobilístico são um exemplo interessante de investimento em tecnologias de inovação pelo fato de automóveis estarem ligados à poluição do ar. Por este motivo, as empresas tiveram de investir forte em inovação para garantir a participação no movimento sustentável, o conforto, o bem-estar, a comodidade, a facilidade e o requinte aos clientes. A busca pela inovação fez com que os carros fossem especificados como trajes: básico, de série, acessórios, etc. O carro básico, sem opcionais de séries, é chamado de "pelado" em anúncio recente. Ademais, cada uma de suas partes passou por desenvolvimentos científicos e tecnológicos para melhor atender às exigências do mercado.

Um anúncio comercial da Volkswagen $(\mathrm{VW})^{8}$ lançada neste ano resume bem a associação entre carros e inovação. Quase todas as marcas exploram os avanços tecnológicos de pneus, motores, freios, bancos, painéis, etc. para persuadir os compradores. Esse comercial chama a atenção por relacionar inovações de diferentes áreas e práticas. A propaganda alia a imagem de uma mão desenhando objetos e pessoas, ao mesmo tempo em que uma voz vai narrando uma história. O slogan da propaganda é: "VW - 60 anos de inovação no Brasil" e o texto da propaganda diz:

Nossa história começa na década de 50. Nessa época um garoto surgiu para conquistar o mundo e inovou,

\footnotetext{
8 Disponível em: <http://www.youtube.com/volkswagendobrasil>.
} 
tornando-se o cara mais jovem a ser campeão mundial com a camisa da seleção [a mão vai desenhando a lápis a figura de Pelé]. Dois anos antes, a VW também fez história fabricando a primeira Kombi com $50 \%$ das peças feitas no país. Aí depois o cachorro conquistou o espaço e o homem conquistou a lua e ainda teve tempo para inventar a primeira máquina fotográfica instantânea. Nos mesmos anos 60, a VW não fez por menos e lançou um carro pequeno, resistente, econômico e diferente de todos os outros. Quando os relógios digitais, computadores pessoais e as primeiras TVs em cores chegaram ao Brasil nos anos 70, esse cara aqui [e o jogador Rivelino vai sendo desenhado] criou o elástico, um dos dribles mais desconcertantes que o futebol brasileiro já produziu. Falando em inovação, nessa época a VW trouxe seu primeiro carro com motor refrigerado a água. Tudo ia bem até os anos 80 entrarem em campo. A década perdida foi um oásis de modernidade, maravilhas tecnológicas, como o lançamento dos primeiros videogames. Sem perder tempo com isso, nossos engenheiros trabalharam duro para lançar o Gol GTI, o primeiro carro nacional com injeção eletrônica. Enquanto a humanidade dava um jeito de se livrar do toca-fitas portátil, do disco laser e do pager, a VW lançava uma tecnologia que chegou nos anos 90 para ficar para sempre, o sistema de freios ABS. Em 2000, a internet e o celular tornaram-se uma realidade em nossas vidas, assim como a conquista do penta, os instant messangers e a criação dos primeiros compactos espaçosos. Na sequência, a VW criou o primeiro carro bicombustível do país, antecipando o surgimento de uma série de ideias geniais que iriam mudar para sempre as nossas vidas. $\mathrm{Nem}$ todas as boas ideias resistem ao tempo. O melhor dessa história é saber que a VW investe em tecnologias 
que duram e que vão continuar fazendo diferença em nossas vidas por muitas e muitas décadas.9

A história narrada é a história da $\mathrm{VW}$, a personagem principal, que participa de outras histórias encenadas no Brasil e no mundo. A narrativa mistura objetos eletrônicos, digitais, acontecimentos mundiais inéditos e marcantes no desenvolvimento das invenções do homem, jogadores de futebol, para contar a sua história na produção de carros e caracterizá-la como inovação. A história da VW se confunde com as outras histórias de inovação, e o texto é marcado pelo recurso à interdiscursividade, como em "Tudo ia bem até os anos 80 entrarem em campo", em que a metáfora "entrar em campo" atribui o efeito de uma ação humana num jogo de futebol para "os anos 80". Os discursos do futebol, das novas tecnologias, invenções, descobertas e do automobilismo se interpenetram, construindo a ideia de rede que marca a inovação.

Também, a inovação é marcada pela repetição do termo primeiro(a), o que remete ao objetivo explicitado na Lei de Inovação no 10.973 , ao considerar que estabelecer no país uma cultura de inovação está amparado na constatação de que a produção de conhecimento e a inovação tecnológica passaram a ditar crescentemente as políticas de desenvolvimento dos países. Nesse sentido, a inovação estimula a competição, que fica explícita nas afirmações repetidas que colocam a marca como a primeira em muitas iniciativas de avanço tecnológico.

A escolha do léxico se volta para o efeito de novidade e de avanço pretendido para contar a história da VW. Os verbos inovar, conquistar, fabricar, inventar, criar produzir, lançar, trabalhar, antecipar, mudar, investir, durar se ligam aos sentidos que constituem a inovação e se referem a ações traçadas para o desenvolvimento. Termos como tecnologia, lançamento, surgimento, criação também contribuem para o efeito de sentido de progresso, desenvolvimento e inovação.

A inovação automobilística é esperada e já não é novidade há muito tempo, mas faz parte de uma rede em que seus enunciados servem de já ditos para a produção de efeitos de novidade tecnológicas em outras esferas de

9 Transcrição do vídeo feita por mim. Grifos meus. 
enunciação. Na formulação de enunciados, como acontecimentos, os já-ditos são a matéria-prima para construir as novidades. Como na inovação, há um aproveitamento constante de enunciados já conhecidos na produção de novos enunciados para a configuração de diferentes objetos, espaços e sujeitos.

A relação entre enunciados de diferentes formações discursivas pode, às vezes, causar o estranhamento, dada a esperada incompatibilidade historicamente construída pelas práticas. Exemplo disso é uma notícia que circulou em 200810: "Igrejas nos EUA oferecem cursos de ginástica para salvar corpo e alma". Conforme os líderes religiosos entrevistados, "ser um bom cristão e se empanturrar de hambúrguer e batata frita não é um comportamento harmônico, devemos cuidar do nosso corpo, que é o templo de Deus, levar uma vida saudável é um modo de crescer em Cristo e glorificá-lo continuamente". Os vários enunciados que apelam para o consumo de práticas que cultuam a beleza dentro de certos padrões garantidos pelas academias de ginásticas sofrem uma apropriação, tornando dizíveis práticas fundamentadas, agora, em preceitos cristãos, mas que, no plano da visibilidade, continuam constituindo formas de apelação do público para consumir coisas que a instituição igreja pode oferecer.

Dentro de uma perspectiva da raridade, como demonstrada por Foucault (1995), tais enunciados emergem de possibilidades oferecidas tanto pelos discursos da bíblia, como ilustra o versículo do livro de Tessalonicenses, no qual se lê que "E o próprio Deus de paz vos santifique completamente; e o vosso espírito, e alma e corpo sejam plenamente conservados irrepreensíveis para a vinda de nosso Senhor Jesus Cristo", quanto pelos discursos que circulam na mídia, inculcando a necessidade de zelar e moldar o corpo. Pelo acúmulo dos dizeres, o enunciado da igreja é autorizado para colocar as academias de ginástica como mote religioso. Assim, podemos ter notícia da existência de uma academia denominada Fit 4 Christ (em forma para Cristo), como se pode ler na notícia. A vaidade e o culto à beleza não são enunciáveis no discurso da igreja, mas aparecem como visibilidade distorcida pelo discurso do corpo glorificado: "No estado norte-americano do Alabama, faz cada vez mais sucesso a conexão entre atividade física e a vida religiosa, inspirada no ensinamento que toma o 'corpo como templo da alma"'.

\footnotetext{
${ }^{10}$ Disponível em: < http://estilo.uol.com.br/ultnot/2008/05/27/ult3617u4768.jhtm>.
} 
Como instituição marcada por práticas discursivas e não-discursivas, a igreja também entra no movimento de inovação e de controle, apelando para tecnologias que possam oferecer saúde, beleza e felicidade.

\section{PRODUZIR INOVAÇÃO: OUTRAS POSSIBILIDADES}

Como foi demonstrado, resumidamente, na seção 1 deste artigo, Luckesi (2012) vê várias possibilidades para inovar em Educação e considera também como práticas inovadoras aquelas que já são constitutivas das instituições escolares. De fato, o discurso da inovação tem permeado as práticas escolares, com a ideia de desenvolvimento de projetos, de formação permanente dos professores, com a implantação do ensino à distância, com a premiação por meio de provas e concursos aplicados aos alunos, com o aparelhamento informatizado das escolas, etc. Muitas técnicas de produção de competitividade são utilizadas como forma de incentivo ao desenvolvimento educacional e de aumento dos índices de escolaridade do país.

A escola se insere, assim, nas tecnologias do biopoder e passa por categorizações, classificações, comparações por meio de números e estatísticas. Para surtirem efeitos, os resultados dessas técnicas de controle são divulgados e comentados pela mídia. Dados comparativos entre escolas, faculdades e universidades são frequentemente apresentados nos veículos midiáticos, construindo concepções que passam a definir essas instituições e seus sujeitos. Aquelas que apresentam melhores notas nas avaliações e inspeções ditam os parâmetros que devem ser seguidos pelas demais. As inovações tecnológicas, representadas por laboratórios, computadores, internet, entram como garantia de sucesso do processo ensino-aprendizagem.

Falar em inovação escolar tem se configurado na ação de numerar, mensurar, comparar o desempenho de professores e alunos, no uso de equipamentos de informática e de segurança, no atendimento empresarial a alunos e pais, nas formas instantâneas de comunicação. Contudo, o objetivo deste artigo é refletir sobre outras possibilidades de inovação sugeridas pela rede de enunciados que forma a base de qualquer outro tipo de inovação científica ou tecnológica. 
Antes de tecer reflexões sobre a produtividade da noção de enunciado formulada por Michel Foucault, é interessante comentar uma matéria exibida, num telejornal ${ }^{11}$, para divulgar os avanços da Neurociência nos estudos sobre o cérebro e sobre o ensino/aprendizagem. O que chama atenção na matéria é a ênfase dada ao papel da capacidade de estabelecer relações. Serão transcritos, a seguir, alguns trechos da matéria:

A leitura é uma das coisas que mais ajudam na memória, que mais exercitam a memória", diz o neurocientista Ivan Izquierdo, da PUC/RS.

$E$ acredite: malhar também faz bem à memória. Pesquisas de universidades americanas mostraram que a prática regular de atividades físicas ajuda a pensar com mais clareza e melhora a aprendizagem.

Aprender é criar novas memórias de longa duração. Um dos maiores especialistas no mundo em memória é categórico. "Todas as memórias são associativas. A memória é um fato associativo", afirma Izquierdo.

Se você associar o que aprende a algum conhecimento antigo, que você já tenha, fica mais fácil guardar para sempre na sua cabeça.

$A$ atividade cerebral é a troca de informações entre neurônios, mas eles não se tocam diretamente. A comunicação se dá através da sinapse, que é a conexão entre neurônios. É a área em que dois neurônios passam informações de um para o outro através de impulsos elétricos. O cérebro nasce com aproximadamente 250 bilhões de sinapses. Aos oito meses, o bebê já fez 600 bilhões de sinapses. Esse excesso de conexões no começo da vida é apenas matéria-prima.

É como se fosse um bloco de gelo bruto. Ali dentro há todas as possibilidades de escultura, mas, por enquanto,

${ }^{11}$ Disponível em: <http://g1.globo.com/jornal-da-globo/noticia/2013/03/carreiras-e-atividades-especificas-ajudam-desenvolver-memoria.html $>$. 
ainda não é nada. Para que este bloco se transforme em uma escultura de fato, todo material que está sobrando tem que ser removido. No cérebro, o que faz essa eliminação é justamente o uso.

Quanto mais a gente usa o nosso cérebro, mais ele vai se definindo. As conexões que a gente não usa vão sendo eliminadas. Aprender muda o cérebro. Somos capazes de modificar a nossa estrutura cerebral até o último dia de nossas vidas. Vários estudos já comprovaram isso.

A pesquisa divulgada e os comentários dos neurocientistas entrevistados mostram que o cérebro realiza atividades de troca de informações entre os neurônios através de conexões, que se ligam a outras conexões antigas que se tornam matéria-prima. A rede de associações, dispositivo de funcionamento da tecnologia e inovação, é o mesmo que faz funcionar o cérebro humano. Sendo a memória associativa, aprender, segundo a teoria acima, "é criar novas memórias de longa duração", a partir de conhecimentos antigos. Logo, a aprendizagem é a inovação primeira, com a possibilidade de se renovar a cada vez que informações novas entrem em conexão com as que já estavam construídas. Essa é a base de entendimento do enunciado na elaboração de Foucault (1995) e das práticas de inovação. Torna-se, assim, possível elaborar que a memória e as práticas discursivas (o enunciável) e as não-discursivas (as visibilidades) estão em constante conexão para que cada uma possa entrar em ação.

O fato de a memória ser associativa só reafirma a importância da leitura no processo ensino-aprendizagem e na vida das pessoas. Nesse sentido, a matéria apresenta exemplos de aplicação das descobertas da Neurociência na Educação, mostrando algumas escolas do Brasil, que já utilizam os seus pressupostos no ensino fundamental, e os resultados positivos na aquisição dos conhecimentos. Conceber o conhecimento como ação e resultado de estabelecer conexões, exige, antes de qualquer coisa, que se considere o exercício do pensar, da reflexão.

Talvez seja nesse ponto que a escola esteja indo na contramão do desenvolvimento científico e tecnológico, pois, é possível observar que, nas práti- 
cas em sala de aula, não há atividades que demandem um tempo de suspensão das ações já constitutivas do espaço escolar, para que os alunos possam pensar, refletir sobre o que se ouve, discute, lê ou escreve. O dito aparece, na escola, como conteúdo a ser assimilado para ser testado. Mas qual a relação de determinado conteúdo com as diferentes teorias e seus conceitos? Em que temas da atualidade ele aparece ou reaparece ou desapareceu? Que tipo de relação há entre as diferentes posições-sujeito que aparecem nesse conteúdo? Em que formações discursivas ele se apoia e qual seu valor em cada uma? São fundamentos trabalhados por Foucault em A arqueologia do saber e que pressupõem a reflexão e a problematização para que um feixe de enunciados possa ser despertado na memória e permitir a busca de outros enunciados em outros domínios e suportes.

A elaboração sobre enunciado de Foucault constitui uma teoria que seria a base de compreensão do processo de formulação e de colocação em uso da linguagem. A noção de enunciado, como unidade do discurso e como nó na rede, poderia ser estendida para as teorizações sobre a aquisição do conhecimento e para as mudanças nas práticas de ensino e aprendizagem. É nesse aproveitamento das formas de funcionamento do que é dito sobre as coisas do mundo que entra a capacidade de inovação, de colocar um determinado conteúdo como nó em uma rede e de buscar suas conexões. A leitura cumpre uma função insubstituível na construção do conhecimento e das formas de estar no mundo. O próprio Foucault (1998), ao afirmar que o discurso, no ocidente, tem ocupado o menor lugar possível entre o pensamento e a palavra, analisa que, ora o conhecimento é considerado como um pensamento revestido de seus signos e tornado visível pelas palavras, ora é visto como depósito na mente de um sujeito fundador que pode manifestá-lo em forma de signos, traços, letras. A relação entre os ditos, que puderam construir os saberes, as normas, os sentidos, os sujeitos, fica elidida, e o pensamento, restrito à sua representação pela palavra ou a um produto da intuição e da intenção de um sujeito fundante. Seguindo esse raciocínio, o autor questiona: "Se o discurso existe, o que pode ser, então, em sua legitimidade, senão uma discreta leitura?" (FOUCAULT, 1998: 48).

A resposta a essa questão é formulada por ele logo a seguir, por meio da explicação de que o conhecimento é um discurso já pronunciado, pois as 
coisas e os acontecimentos se tornam discurso, uma reverberação de uma verdade que desponta diante de um novo acontecimento. O discurso, na formulação de Foucault (1998), é um jogo de escritura, de leitura e de troca.

A escritura é resultado do jogo disputado entre os ditos que poderão compor o texto que surge, conforme o tema, o objeto tratado, a função enunciativa e as restrições impostas pela situação de produção. A leitura é a possibilidade de fazer as coisas e os sentidos falarem, de conhecê-los, nomeá-los, julgá-los. A troca é o jogo de intercâmbio dos sentidos de tudo o que pôde ser dito. Trata-se de um jogo, em que as peças atuam de forma integrada, numa interdependência de função. A escritura requer que se tenha o que dizer, ou seja, depende da massa de enunciados já formulados sobre o conhecimento em questão, que só podem ser acessados por meio da leitura e relacionados por meio da troca de sentidos entre os enunciados já conhecidos e aqueles que estão no processo de interpretação.

Esse jogo não é reservado somente às aulas de Português, Linguística ou literatura, mas é jogado por todas as áreas do saber, mesmo que não haja consciência sobre essa elaboração teórica. Nesse sentido, a reflexão sobre esse jogo para a tomada de consciência de suas regras e estratégias de funcionamento torna-se imprescindível para compreensão e a realização do ato de conhecer. Foucault (2000c: 71) esclarece sobre esse ponto, demonstrando que as várias áreas do conhecimento "estão articuladas à rede de todas aquelas que falam da 'mesma coisa', que lhes são contemporâneas e lhes sucedem: essa rede que as envolve delineia essas grandes figuras sem estado civil que chamamos de 'matemática', 'história, 'biologia'.... O autor demonstra, ainda, que esses procedimentos de pesquisa se formam uns em relação aos outros e que existem uns para os outros.

Com base nessa elaboração, pode-se deduzir que a interdisciplinaridade, já proposta como forma de lidar com o conhecimento, permitiria a conexão entre os saberes. Contudo, atualmente, pelo que se vê nas práticas de ensino, nos materiais didáticos, a rede construída para se fazer a interdisciplinaridade procura conectar disciplinas, e não saberes que sejam ou não científicos, procura aproximar conteúdos já apropriados e racionalizados pela disciplina. A rede de que fala Foucault e de que vive a inovação é interdiscursiva, pois opera com a existência acumulada dos discursos, ou, nos termos de Foucault (1995), com o arquivo. 
A noção de arquivo elucida o fato de se considerar o enunciado como a unidade do conhecimento e auxilia na reflexão acerca da função de se estabelecer relações na leitura e na escritura. Conforme Foucault (1995: 149), o arquivo é "a lei do que pode ser dito, o sistema que rege o aparecimento dos enunciados como acontecimentos singulares [...] o que faz com que todas as coisas ditas [...] se agrupem em figuras distintas, se componham umas com as outras segundo relações múltiplas”.

A metáfora da rede, assim, instiga à reflexão acerca das concepções de ensino da leitura e da escritura na escola, redimensiona a importância do ato de ler e redefine o tipo de matéria-prima que permite a produção de um texto. A matéria-prima são os enunciados que vão compor o arquivo que se coloca para a leitura e para a formulação de outros enunciados acontecimentos. Assim, parafraseando Foucault (1995), qualquer objeto de conhecimento é constituído pelo conjunto daquilo que foi dito no grupo de todos os enunciados que o nomeiam, recortam, descrevem, explicam, contam seus desenvolvimentos, indicam suas diversas correlações, julgam-no e emprestam-lhe a palavra, articulando, em seu nome, discursos que devem passar por seus. Os ditos, potencialmente, apontam na direção do objeto a ser produzido, mas essa convergência entre os discursos não significa que é o mesmo objeto descrito em cada discurso, pois a realidade do objeto comporta a dispersão entre os ditos e compõem também com suas divergências. Os conjuntos de enunciados estabelecem entre si jogos, jogos de poder cuja resultante faz emergir o objeto produzido. Esses jogos de relações constituem um princípio de determinação que abriga ou exclui, no interior de um dado discurso, certo número de enunciados e que integra, por meio da função discursiva, as práticas não-discursivas.

Como se trata de relações, a prática de ensino de leitura e escrita não poderia ser pautada e nem transformada em métodos, ou em unidades definidas e delimitadas por um conteúdo. São os próprios enunciados lidos, interpretados que mostram a trilha a percorrer para a construção dos conhecimentos, pois o que o mundo das coisas ditas conhece são invasões, lutas, disfarces, artimanhas (FOUCAULT, 2000a). O conhecimento não oferece facilidades; é preciso seguir por caminhos tortuosos, íngremes, circulares, labirínticos. As palavras, antes de serem signos, interpretam, e há um tempo 
da interpretação, que é circular. Esse tempo, conforme Foucault (2000a), é obrigado a passar novamente por onde ele já passou, sem que isso impeça ou atrapalhe a interpretação. A morte da interpretação seria acreditar que há signos que existem primeiramente, originalmente, realmente, como marcas coerentes, pertinentes e sistemáticas.

\section{CONSIDERAÇÕES FINAIS}

Diante das considerações que puderam ser tecidas neste artigo, é possível analisar que o fato de as práticas de ensino não terem se voltado à produtividade e à inovação das estratégias associativas está ligado à visão de que o signo, com sua estabilidade, coerência e sistematicidade deva preceder as atividades de interpretação e de produção textual. Contudo, a relação entre discursos e práticas de diferentes instâncias, já há um tempo considerável, vem sendo exploradas por outras esferas da comunicação e do conhecimento, o que não se nota quando se trata do ensino de Língua Portuguesa.

Foucault (1996), tomando como ponto de partida as ideias de Nietzsche, afirma que o conhecimento foi inventado, que ele não está inscrito na natureza humana; ele é resultado do jogo, do afrontamento, da junção, da luta, do combate; é violação das coisas a conhecer e não percepção, reconhecimento, identificação delas ou com elas. Nesta mesma obra, Foucault mostra que as práticas sociais do controle e da vigilância podem engendrar domínios de saber, fazendo aparecer novos objetos, novos conceitos, novas técnicas e fazendo nascer formas novas de sujeitos e de sujeitos de conhecimento. A inovação é resultado da configuração dessa sociedade de controle e é, ao mesmo tempo, estratégia poderosa para mantê-la funcionando. Como forma de produzir um efeito de finalização deste trabalho, destaca-se que as problematizações aqui construídas apontam para a falta do exercício de reflexão que predomina nas práticas de ensino atualmente, uma vez que os conhecimentos permanecem reduzidos a conteúdos lineares, com interpretações, julgamentos, avaliações já traçados e com verdades já desvendadas, dispensando, assim, o exercício de construção de relações que, fora da escola, é a forma de conhecer o mundo que o indivíduo domina desde os 
primeiros meses de vida. Espera-se, assim, que este texto se constitua como um nó na rede para fazer sentido em sua relação com aqueles que já vieram antes e com aqueles que ainda virão para ampliar o conhecimento e contribuir para a tomada de consciência do trabalho associativo empreendido pela memória na aprendizagem e para a reflexão sobre a trajetória cumprida pelos enunciados na construção dos sentidos renovados ou novos das práticas discursivas e não-discursivas.

\section{REFERÊNCIAS BIBLIOGRÁFICAS}

BRASIL. Lei de Inovação n. 10.973. Brasília: Planalto/Casa Civil, 2004.

DELEUZE, G. Foucault. São Paulo: Brasiliense, 2005.

. Conversações. São Paulo: Editora 34, 1992.

DUARTE, A. Biopolítica e resistência: o legado de Michel Foucault. In: RAGO, M.; VEIGA-NETO, A. Figuras de Foucault. Belo Horizonte: Autêntica, 2008.

FOUCAULT, M. A arqueologia do saber. Rio de Janeiro: Forense Universitária,1995.

. A verdade e as formas jurídicas. Rio de Janeiro: Nau, 1996.

. A ordem do discurso. São Paulo: Loyola, 1998.

. Em defesa da sociedade. São Paulo: Martins Fontes, 1999.

. Nietzsche, Freud, Marx. In: FOUCAULT, M. Arqueologia das ciências e história dos sistemas de pensamento. Ditos e Escritos II. Rio de Janeiro: Forense Universitária, 2000a. 
Sobre a arqueologia das ciências. Resposta ao círculo de epistemologia. In: FOUCAULT, M. Arqueologia das ciências e história dos sistemas de pensamento. Ditos e Escritos II. Rio de Janeiro: Forense Universitária, 2000b.

. Sobre as maneiras de escrever a história. In: MOTTA, M. B. da (Org.) Foucault: arqueologia das ciências e história dos sistemas de pensamento. Ditos e Escritos II. Rio de Janeiro: Forense Universitária: 2000c.

. História da sexualidade I: a vontade de saber. Rio de Janeiro: Graal, 2001.

. Microfísica do poder. Rio de Janeiro: Graal, 2003.

. O cuidado com a verdade. In: MOTTA, M. B. da (Org.) Foucault: Ética, sexualidade, política. Ditos e Escritos V. Rio de Janeiro: Forense Universitária, 2004.

. É importante pensar?. In: FOUCAULT, M. Arqueologia das ciências e história dos sistemas de pensamento. Ditos e Escritos II. Rio de Janeiro: Forense Universitária: 2010.

. Entrevista com Michel Foucault. In: FOUCAULT, M. Arqueologia das ciências e história dos sistemas de pensamento. Ditos e Escritos II. Rio de Janeiro: Forense Universitária: 2011a.

. Foucault, o filósofo, está falando. Pense. In: FOUCAULT, M. Arqueologia das ciências e história dos sistemas de pensamento. Ditos e Escritos II. Rio de Janeiro: Forense Universitária: 2011b.

LUCKESI, C. C. Educação, Avaliação Qualitativa e Inovação. Instituto Nacional de Estudos e Pesquisas Educacionais Anísio Teixeira, 2012. Disponível em: http://www.publicacoes.inep.gov.br/arquivos/\%7B37A31349-999C4F13-A56E-E5DEAF09ED11\%7D_TD\%2037.pdf. Acesso 26 mar 2013. 
PELBART : P. Vida capital: ensaios de biopolítica. São Paulo: Iluminuras: 2003.

TEDESCO, S. Subjetividade e seu plano de produção. In: QUEIROZ, A. CRUZ, N. V. (Org.) Foucault hoje? Rio de Janeiro: 7Letras: 2007. 
